\title{
Infantile Exogenous Cushing Syndrome due to Misuse of Topical Corticosteroid
}

\section{Abolhassan Seyedzadeh*}

Department of Pediatrics, Head of Ped Nephrol Division, Emam Reza Educational Hospital, Kermanshah, Iran

\begin{abstract}
Background: Topical Corticosteroids have been ordered in Medical practice by many doctors for Various Skin diseases but prolong use of these Medication causes Systemic adverse effects including Cushing Syndrome. latrogenic Cushing Syndrome may occur with over use of potent topical steroids mostly due to Diaper dermatitis.

Case report: We report a 3 month old female infant who developed Cushing Syndrome after diaper dermatitis treatment through misuse of Clobetasol without doctor's Prescription. After diagnosis, the application of this topical corticosteroid was stopped and physiologic dose of prednisolon was prescribed to prevent an adrenal crisis for 2 months.

Conclusions: Continuous use of moderate to high potency topical corticosteroids over several months can contribute to cushing's syndrome. So parents must be informed by physicians about the adverse effect of steroids and they should be avoided in very young infant.
\end{abstract}

Keywords: Cushing syndrome; Diaper dermatitis; Adrenal insufficiency; Corticosteroid

\section{Introduction}

Iatrogenic Cushing Syndrome may occur with the over use of potent Steroid's [1] but only those labeled as low potency are acceptable for chronic use in infant and young children. High Potency local steroids are used primarily as an alternative to systemic corticosteroids [2] although local absorption of these products may lead to sever systemic side effect. These adverse side effects depending on duration of usage and potency of corticosteroid. Cushing's syndrome concomitant with hypothalamic - pituitary - adrenal axis suppression is a potential Systemic adverse effect caused by improper and prolong use of super potent topical corticosteroid [1].

\section{Case Report}

A 3 month old girl was referred to our hospital due to obesity and excessive weight gain from about 2 months ago. She was the first child of a healthy family from normal delivery with Birth weight of $3200 \mathrm{~g}$ (50th percentile).

A physical examination showed clear truncal obesity and moon face appearance. Her Body weight on admission was $8 \mathrm{~kg}$ (above 97th percentile).

9 Vital Signs revealed a body temperature of $37^{\circ} \mathrm{C}$ and Blood pressure of $\frac{95}{65} \mathrm{~mm}$ hg. (Under 95th percentile).

The patient had diaper dermatitis from about 2 months ago and her mother use clobetasol 3-4 times in day from that time laboratory evaluation showed:

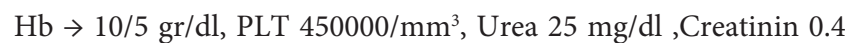
mg/dl, Sodium 138 ,Potassium 4.7, ACTH 3.04 pg/ML (Nl 4.7-48.8), cortisol $3.98 \mu \mathrm{g} / \mathrm{dl}$ (Nl 60-285).

The application of this topical corticosteroid was stopped and $5 \mathrm{mg}$ prednisolon was prescribed for 7 days and tapered and stopped after 2 weeks, after 5 month follow up, weight percentile dropped under 97th percentile for age and sex.

\section{Discussion}

The First therapeutic use of glucocorticoid in 1948 resulted in dramatic clinical improvement in patients severs rheumatoid arthritis. Almost immediately, the potential adverse effect of exogenous steroid administration became evident [3]. Glucocorticoids are a class of steroid hormones [4].

Glucocorticoids generally are absorbed well from various sites of application [3]. Topical corticosteroids can be absorbed from intact healthy skin $(4,5)$. But inflammation or other disease processes in the skin may increase per cutaneous absorption [5] potent topical corticosteroids should be avoided under the age of 12 years old [3-5]. Because of a higher ratio of skin surface area to body mass, pediatric patients are at a greater risk than adult of hypothalamic -pituitary - adrenal axis suppression when they are treated with topical corticosteroids [5]. Clobetasol is one of the most super potent topical corticosteroid [3]. So treatment with clobetasal not recommended more than two weeks and the total dosage should not exceed $150 \mathrm{~g}$ per week in children [4,5]. Although over dose of local glucocorticoids including local adverse effects like hypo pigmentation ,atrophy, acne, striae, purpura [2,3] but the more dangerous systemic adverse effects is cushing's syndrome $[3,5]$. Cushing's Syndrome develops when the level of a glucocorticoid in our body is too high level over a long period of time. Too much glucocorticoid can occur from an exogenous or endogenous source [6,7]. Exogenous Cushing's Syndrome present with the some sigh and symptom as spontaneous cushings syndrome $[3,6,7]$ and include weight gain, central obesity, Hypertension ,facial plethora, hyperlipidemia, Easy bruising, and osteoporosis $[6,8]$ in many cases the diagnosis of exogenous crushing's syndrome should be fairly obvious in the setting of treatment with High dose of glucocorticoids $[2,3]$. The most important biochemical finding in exogenous Cushing's

*Corresponding author: Abolhassan Seyedzadeh, Department of Pediatrics, Head of Ped Nephrol Division, Emam Reza Educational Hospital, Kermanshah, Iran, Tel: 0098831 4276310; Fax: 0098831 4276343; E-mail: cdelilbasi@yahoo.com

Received April 06, 2012; Accepted July 24, 2012; Published July 27, 2012

Citation: Seyedzadeh A (2012) Infantile Exogenous Cushing Syndrome due to Misuse of Topical Corticosteroid. J Clin Case Rep 2:179. doi:10.4172/21657920.1000179

Copyright: ( $\odot 2012$ Seyedzadeh A. This is an open-access article distributed under the terms of the Creative Commons Attribution License, which permits unrestricted use, distribution, and reproduction in any medium, provided the original author and source are credited. 
Citation: Seyedzadeh A (2012) Infantile Exogenous Cushing Syndrome due to Misuse of Topical Corticosteroid. J Clin Case Rep 2:179. doi:10.4172/2165-7920.1000179

Syndrome are low level of corticotropin (ACTH) and serum cortisol $[2,8]$.

Most case of exogenous cushing's Syndrome are iatrogenic, however, there have been a few reports, Mostly in children of iatrogenic cushing Syndrome caused be potent topical corticosteroids $[7,8]$ and most affected cases in children group were an infant with diaper dermatitis [2] our patient also started with diaper dermatitis super imposed with Candida infection and she had typical clinical finding of Cushing Syndrome with cortisol and ACTH Suppression. After diagnosis, the appropriate management to prevent adrenal insufficiency after cessation of causative agent done by given a physiologic dose of steroid.

So to diagnose and good management of adverse effects of topical corticosteroids, clinicians should know about signs and symptoms of iatrogenic Cushing's syndrome, and parents should avoid to use potent topical corticosteroid in very young infant by itself.

\section{Conclusion}

Misuse or extensive use of topical steroids can cause Cushing syndrome, awareness of the side effects including Cushing syndrome, is important when prescribing steroid containing medication.

Warning parents about potential hazardous effect of steroids, limiting steroid containing medication, and also parents of Cushing syndrome infant should be asked whether they have applied any topical steroid's or other steroid containing drugs to their child.

\section{References}

1. Selahattin Katar, Sedat Akdeniz, M Nuri Ozbek, Ahmet Yaramis (2008) Infantile iatrogenic Cushing's syndrome. Indian J Dermatol 53: 190-191.

2. Tempark T, Phatarakijnirund V, Chatproedprai $\mathrm{S}$, Watcharasindhu $\mathrm{S}$ Supornsilchai V, et al. (2010) Exogenous Cushing's syndrome due to topica corticosteroid applocation: case report and review literature. Endocrine 38: 328-334.

3. Hopkins R, Leinung M (2005) Exogenous Cushing's syndrome and glucocorticoid withdrawal. Endocrinol metab clin North Ame 34: 371-384.

4. Richter B, Neises G, Clar C (2002) Glucocorticoid withdrawal schemes in chronic medical disorders. A syetemic review. Endocrinol metab clin North Ame 31: 751-778.

5. Rahmayunita G, Pulugan AB, Wiryadi BE, Wisesa TW, Sugito TL, et al. (2008) Cushing syndrome induced by misuse of topical corticosteroid in a child with psoriasis vulgaris. Med $\mathrm{J}$ Indones 17: 281-286.

6. Coureau B, Bussieres JF, Tremblay S (2008) Cushing's syndrome induced by misuse of moderate to high potency topical corticosteroids. Ann Pharmacother 42: $1903-1907$.

7. Siklar Z, Bostanci I, Atli O, Dallar Y (2004) An infantile Cushing syndrome due to misuse of topical steroid. Pediatr Dermatol 21: 561-563.

8. Joe E (2006) Cushing syndrome secondary to topical glucocorticoids. Dermatol online J 9: 16. 